\title{
Diversity of weevils in rice mills of Tehsil Gujrat, Punjab, Pakistan
}

Haleema Zafar ${ }^{1}$, Sumera Afsheen ${ }^{1}$, Abdul Rauf Bhatti ${ }^{2}$, Muhammad Faheem Malik ${ }^{1}$, Saiyed Ahmed Zia ${ }^{2}$, Sidra Mubeen ${ }^{1}$ and Sadia Sidra $\mathrm{Aziz}^{1 *}$

1. Department of Zoology, Hafiz Hayat Campus, University of Gujrat, 50700, Gujrat, Punjab-Pakistan

2. National Insect Museum, National Agriculture Research Centre, 44000. Islamabad-Pakistan

*Corresponding author's email: sadia.sidra.aziz@gmail.com

Citation

Haleema Zafar, Sumera Afsheen, Abdul Rauf Bhatti, Muhammad Faheem Malik, Saiyed Ahmed Zia, Sidra Mubeen and Sadia Sidra Aziz. Diversity of weevils in rice mills of Tehsil Gujrat, Punjab, Pakistan. Pure and Applied Biology. Vol. 10, Issue 3, pp751-760. http://dx.doi.org/10.19045/bspab.2021.100077

\begin{tabular}{llll}
\hline \hline Received: 07/08/2020 & Revised: 29/10/2020 & Accepted: 27/11/2020 & Online First: 05/12/2020 \\
\hline
\end{tabular}

\section{Abstract}

Weevils belonging to the genus Sitophilus (Order Coleoptera and Family Curculionidae) cause a great loss to stored grains like maize, rice, wheat, barley, macaroni etc. If unchecked, these pests can cause a great loss every year in stored grains. The present study is based on finding the Diversity of weevils in rice mills of Tehsil Gujrat, Punjab, Pakistan. A total of 315 samples were collected from nine sites in five months, which belonged to three different species; then brought to the lab and identified under a stereoscope. Three species found in rice mills were Sitophilus zeamais, Sitophilus oryzae and Sitophilus granarius. Diversity was similar throughout, but abundance varied concerning temperature and humidity. As these two parameters increased, abundance also increased. Humidity was highest in August and so was abundance. The ratio of female weevils was more than male weevils. The correlation came to be positive between the two parameters and Diversity.

Keywords: Diversity; Sitophilus granarius; Sitophilus oryzae; Sitophilus zeamais; Stored grains

\section{Introduction}

Granaries such as wheat and rice are attacked by small insects such as weevils and beetles. The higher temperature in summer favors the growth of these pests [1]. Some weevils hide inside the seeds as eggs or larval stages when brought for storage and only appear when they are mature or reach the adult stage and move to the other seeds thus causing destruction. The number of weevil species that have been reported so far is about 62000 , and the existing species are about 220,000 [2]. According to another estimate loss caused by insect-pests in stored grains worldwide is $10-40 \%$ [3].
Weevils belong to the super family Curculionidea and hold a large portion of well-known species of the order Coleoptera [4]. Some weevils have snout as long as their body length. Major types of weevils attacking grains belong to Sitophilus species [5]. Various survey programs have shown that infestation caused by weevils is seasonal or timely and varies between different months of the year [6]. The present study was carried out during other months of the year to check out the species Diversity as the species Diversity and factors affecting are unaddressed so far in the Gujrat area of Pakistan. Gujrat is located between two rivers of Pakistan i.e. Chenab and Jhelum. The total area of 
District Gujrat is about 1232.4 Miles², or $3192 \mathrm{~km}^{2}$. It is located $32^{\circ} 34^{\prime} 25.67^{\prime \prime} \mathrm{N} 74^{\circ} 4^{\prime} 44.18^{\prime \prime} \mathrm{E}$ according to geographic coordinates. The study was conducted based on sampling from different rice mills of Tehsil Gujrat. Sites were visited at different times of month from April to August 2016 for the collection of samples.

Much of the work has been done on Sitophilus genus around the world but work on the respective species lay neglected so far in Pakistan according to my findings. Many species of weevils cause destruction in storages around the world. Temperature and moisture conditions of store houses are usually favorable for weevils to grow and flourish [7]. This phenomenon was also supported in the present research work.

Stored grain insect pests cause as much damage to the grains as do the pests on crops before harvesting. Because of potential for economic damage caused by stored product insects, there is a growing need for better understanding of not only behavior of stored product insects but also their ecology to be used in developing better and safer pest management [8]. The efficient control of insect pests depends upon the knowledge of particular species and their Diversity. Therefore, current study was designed to know about the Diversity of species found so that further work can be carried to control the growth and prevalence of weevils as no record has been found on this project ever before in this area to the best of our knowledge. The objectives of this research were to find the Diversity of weevil species in rice mills of Tehsil Gujrat and to discover new species of weevils, if any.

\section{Objectives}

1. To explore species of weevils in granaries of Tehsil Gujrat, Punjab Pakistan.

2. To find species Diversity due to variation in temperature and moisture conditions.

\section{Materials and Methods}

The samples were collected from 9 wellknown rice mills of Gujrat area. Weevils were separated from samples using sieve with mesh of $1 \mathrm{~mm}$ round modified after Pereira et al. [9]. Collected samples were killed in $70 \%$ ethanol [10] and preserved in 70-80\% ethyl alcohol [11].The samples were then identified under stereoscope using key modified after Dobie et al [12]. Insects and arachnids of tropical stored products, their biology and identification (a training manual) and an identification guide by Bousquet was also followed [13]. After identification specimens were pinned properly in insect box and naphthalene balls were placed in boxes for dry preservation of specimens and prevent them from spoilage. Collection was stored in zoological museum in department of Zoology University of Gujrat, Punjab, Pakistan. The collected data was analyzed by using Microsoft excel 2010. Statistical analysis was done using SPSS (Statistical Package for Social Sciences). Moreover, species diversity was calculated using Shannon diversity index. Species richness was found using Margalef's diversity index.

\section{Results and Discussion}

Total nine rice mills were visited in Tehsil Gujrat from April to August 2016. The rice mills had almost similar conditions with minor fluctuations. These conditions were temperature, storage conditions and humidity. Diversity was dependent upon humidity and temperature conditions. The results indicated that Diversity and richness remained constant whereas abundance increased with increasing temperature and humidity. It is supported by Ahmad (1956) that more humid conditions support more attack of pests including Sitophilus species [14]. Overall 315 specimens of weevils were collected in these months. The collected weevils belonged to genus Sitophilus and three species granarius, zeamais and oryzae. Out of these 138 (43.8\%) were S.granarius, 92 (29.2\%) S.zeamais and 85 (27\%) S.oryzae. Among all the specimens $42.9 \%$ were males and $57.1 \%$ females. Pupal or larval stages were not found as they pass these stages inside rice grains. Longer the time period of storage more abundant would be species as 
supported by Tara et al. and Sharma et al. $[4,15]$. It was also found in this study that female ratio is higher than the male ratio which is also supported by Danho et al. [16].

Key to species and genus of specimens Sitophilus species of weevils are dark brown to black in color, have long snout, elbowed antennae, body pitted with numerous punctures and elytra present.

Key for the recorded species of Sitophilus genus

1. Body uniformly reddish brown with no spots over elytra; no wings present under elytra, intervals over elytra wider than striae; pronotal punctures elongate as well as distant; Females with thin rostrum, flat abdomen and a wide belt separating pronotum and mesonotum. Males having curved abdomen, rostrum slightly less curved and narrow belt granarius.

2. Body black with four yellow to orange elytral spots; wings under elytra present, intervals on elytra narrower than strial apertures; punctures on pronotum rounded or slightly elongate and closer; Rostrum thicker and small in male while it is thin and long in females 2 .

3. Pronotum lacking any punctures at mid line dorsally oryzae.

4. Large number of pronotal punctures present dorsally with no free zone near midline zeamais

\section{First species: Sitophilus granarius}

Sitophilus granarius was distinguished very easily from other two species on the basis of its morphology. It is reddish brown in color with no spots over elytra. There are no wings present beneath elytra but if they are found, they are vestigial only. Male and female are distinguished on the basis of the abdomen, rostrum and a belt between pronotum and mesonotum. Females have flat abdomen, long thin rostrum and a wide belt separating mesonotum and pronotum. Whereas males have opposite characters like curved abdomen, narrow belt and less curved rostrum. (Fig. 1-8).

\section{Second species: Sitophilus zeamais}

Weevils belonging to this species look much like oryzae species. They are mostly black in color. They have four yellow to orange spots present on elytra. Wings are present beneath elytra. The difference between male and females is one on the basis of rostrum which is thick and small in female but thin and long in male. Secondly this species can be differentiated from oryzae by the absence of a puncture free zone present dorsally in middle portion of pronotum. Large number of punctures is present uniformly throughout (Fig. 9-12).

\section{Third species: Sitophilus oryzae}

Third species of Sitophilus is oryzae which is similar to zeamais in physical appearance. The basic difference is on the basis of punctures present on pronotum. Though they are densely packed but there is a puncture free zone present at mid line. It has four orange spots present on elytra and wings present under elytra. Female has thick and small rostrum whereas male has long and thin rostrum. (Fig. 13-15).

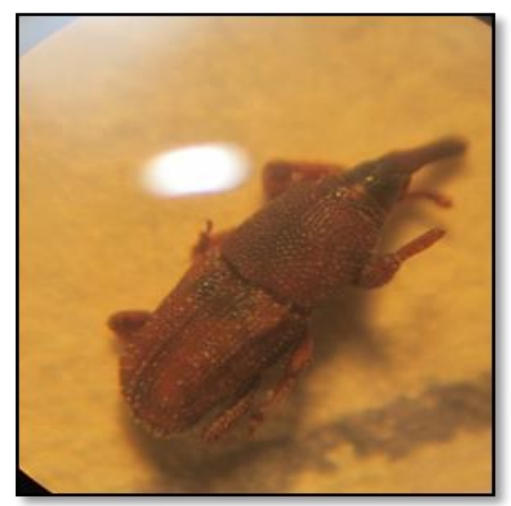

Figure 1. General body plan of granarius male showing uniform body color. Narrow belt visible 


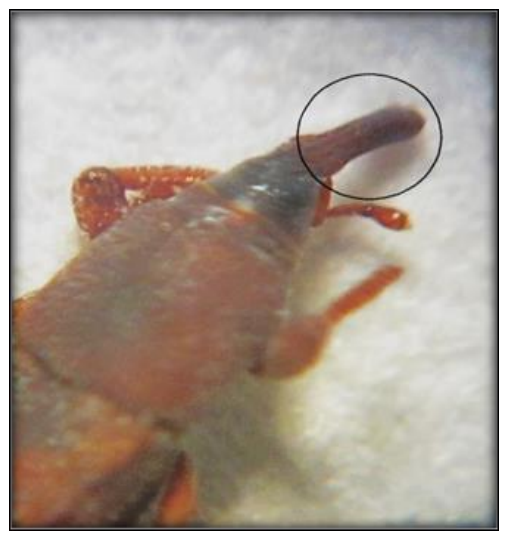

Figure 2. Rostrum of granaries (male) less curved and thick

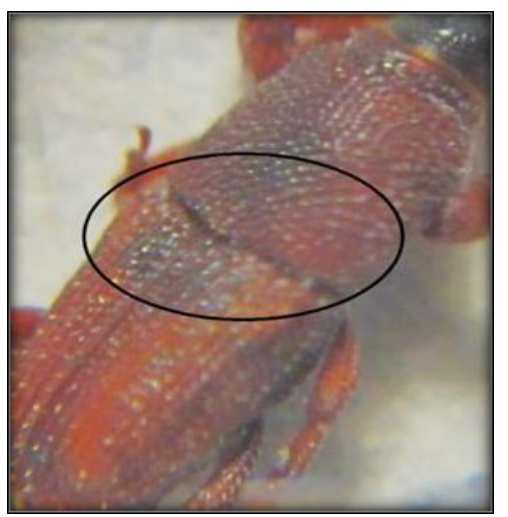

Figure 3. Narrow belt between pronotum and mesonotum of male granaries

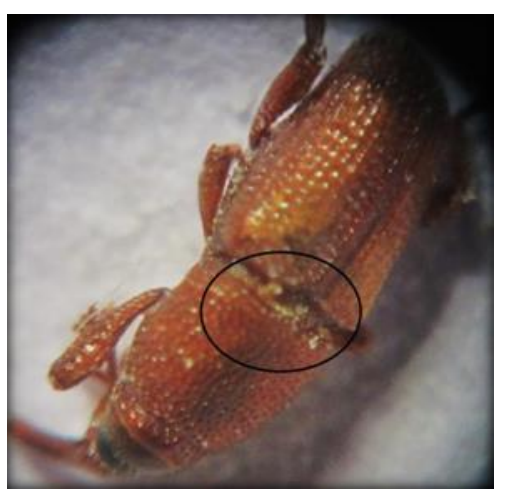

Figure 4. A wide belt present between pronotum and mesonotum of female granaries

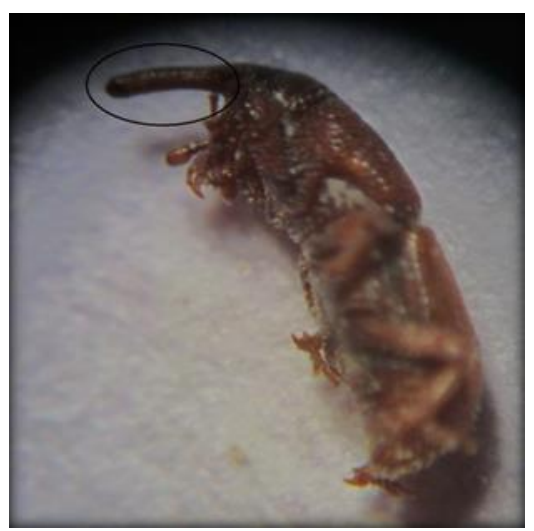

Figure 5. Long thin rostrum and curved downward of granarius female 


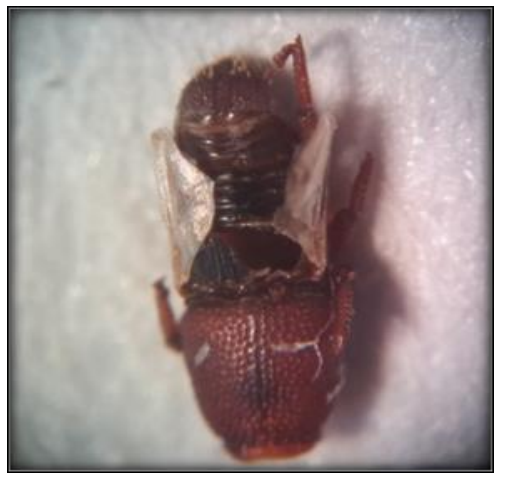

Figure 6. Vestigeal wings of S.granarius beneath elytra

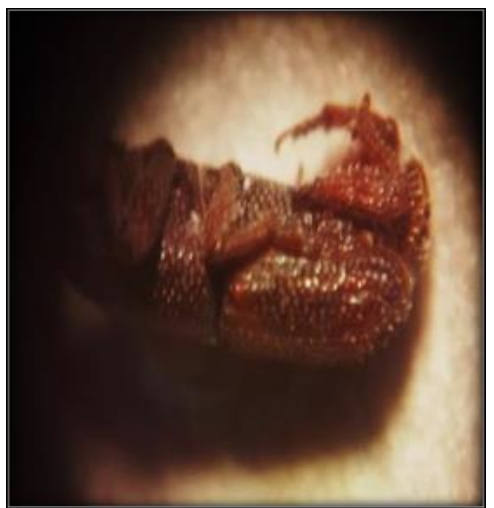

Figure 7. Curved abdomen of male granarius species

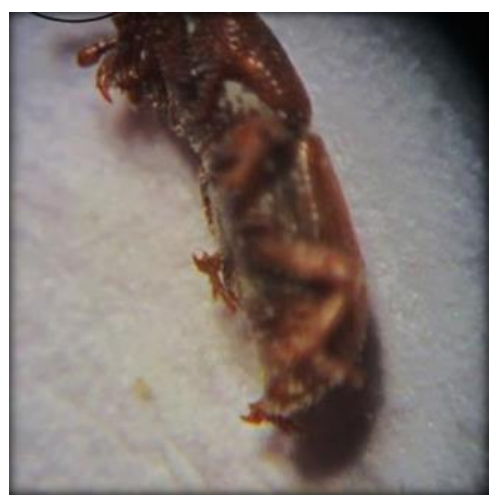

Figure 8. Flat abdomen of female granarius specie

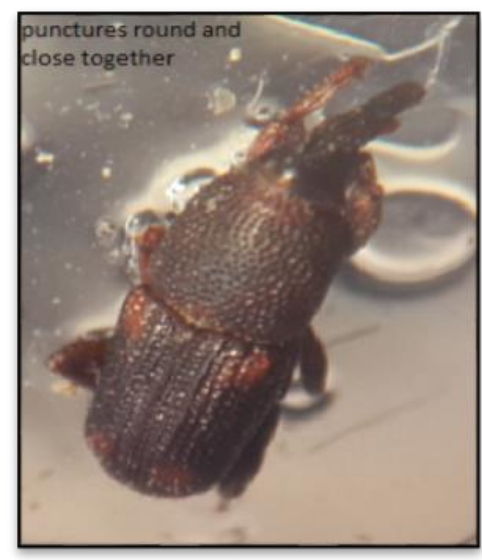

Figure 9. Male of zeamaise species having four clear orange spots on elytra and dense uniform punctures on pronotum 


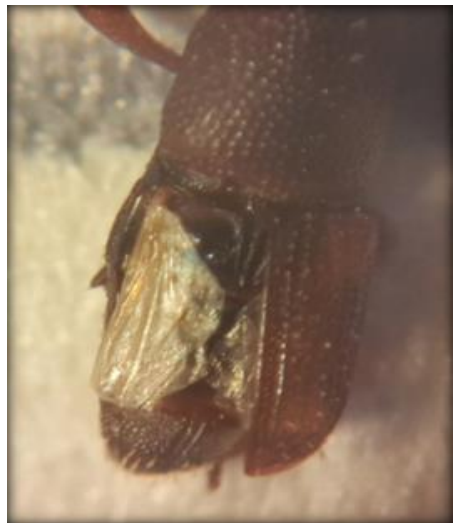

Figure 10. Wings present beneath elytra of zeamaise

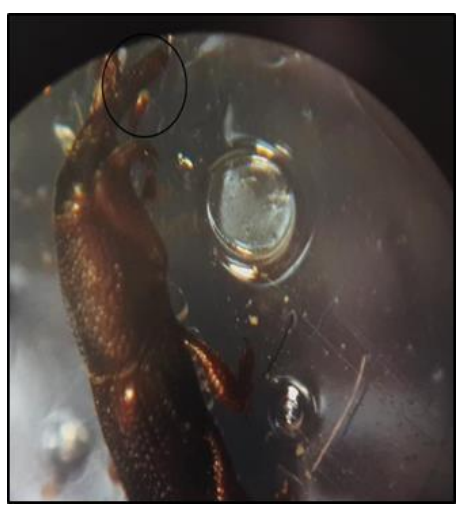

Figure 11. Rostrum thick and small of zeamais female species

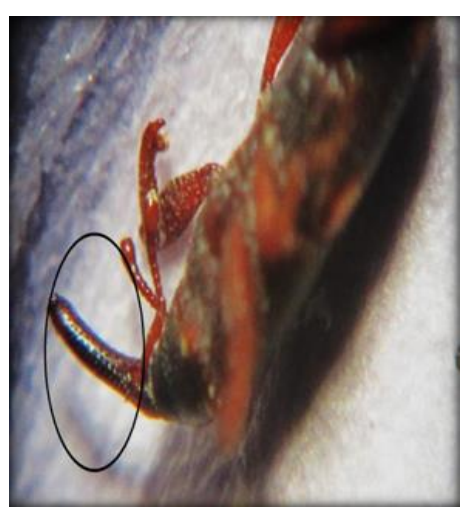

Figure 12. Rostrum of zeamais thin and long (male)

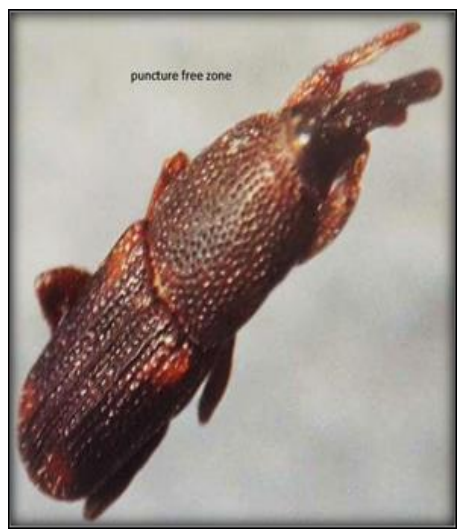

Figure 13. Puncture free zone on pronotum, elytra having four yellow spots (male oryzae) 


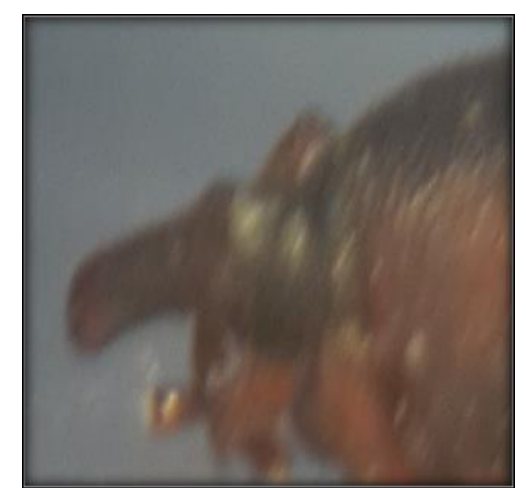

Figure 14. Short and thick rostrum of female $S$. oryzaespecie

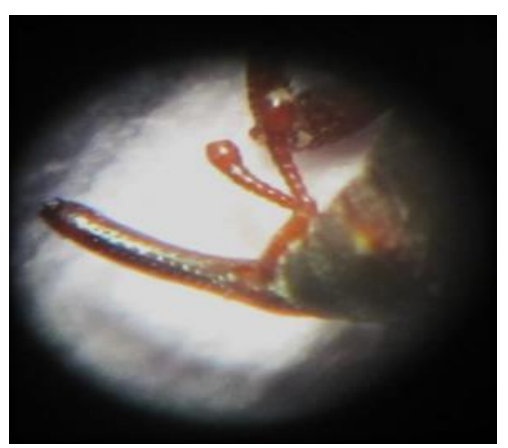

\section{Figure 15. Long and thin rostrum of male S.oryzae species}

\section{Species diversity and abundance}

Species diversity was analyzed using Shannon index. The value of Shannon index for April was 1.02, May 1.06, June 1.08, July 1.05 and August 0.98 abundance of S.granarius was found to be $43.8 \%$, S.zeamais $29.2 \%$ and S.oryzae 27\%. The values of Shannon index indicate less Diversity due to less evenness and richness throughout whereas abundance increases.

\section{Species richness and dominance}

Species richness was analyzed using Margalef's richness index. The values for species richness for each month came out to be 0.62 for April, 0.60 for May, 0.56 for June, 0.43 for July and 0.41 for August. S.granarius was found to be a dominant species. The richness was found to be constant in five months.

Month-wise analysis of species of tehsil gujrat

During the collection 24 weevils were collected in April out of which there were 10 S.oryzae, $10 \quad$ S.zeamais and 4 S.granarius. In May 27 weevils were collected out of which 9 were S.oryzae, 12 S.zeamais and 6 S.granarius. In June 36 samples were collected out of which 9 were S.oryzae, 13 S.zeamais and 14 S.granarius. In July 100 weevils were collected out of which 25 were S.oryzae, 27 S.zeamais and 48 S.granarius. In August 128 weevils were collected out of which 32 were S.oryzae, 30 were S.zeamais and 66 S.granarius. Altogether there were 50 males and 88 females of S.granarius, 42 males and 50 females of zeamais, 43 males and 42 females of S.oryzae. On the whole female species were dominant on male species. (Graph 1, 2).

\section{Correlations}

Results between correlation of weevils' population, humidity and temperature showed that they are very closely related to each other. Increase in temperature and humidity has positive effect on population but humidity plays more significant role. With the increase in humidity population of weevils increases. (Table $1 \& 2$ ). 
Zafar et al.

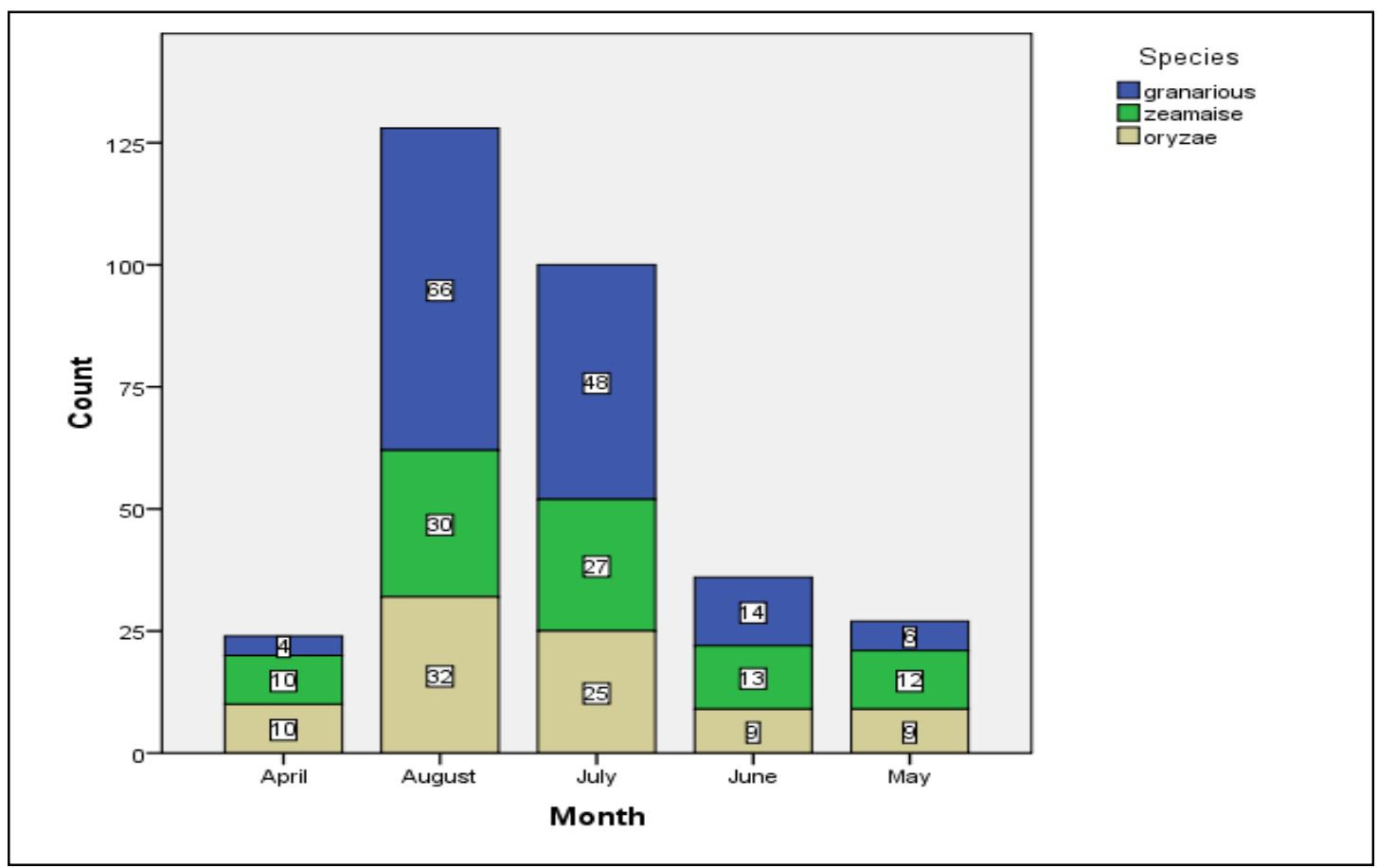

Graph 1. Showing comparative distribution of 3 species in five months

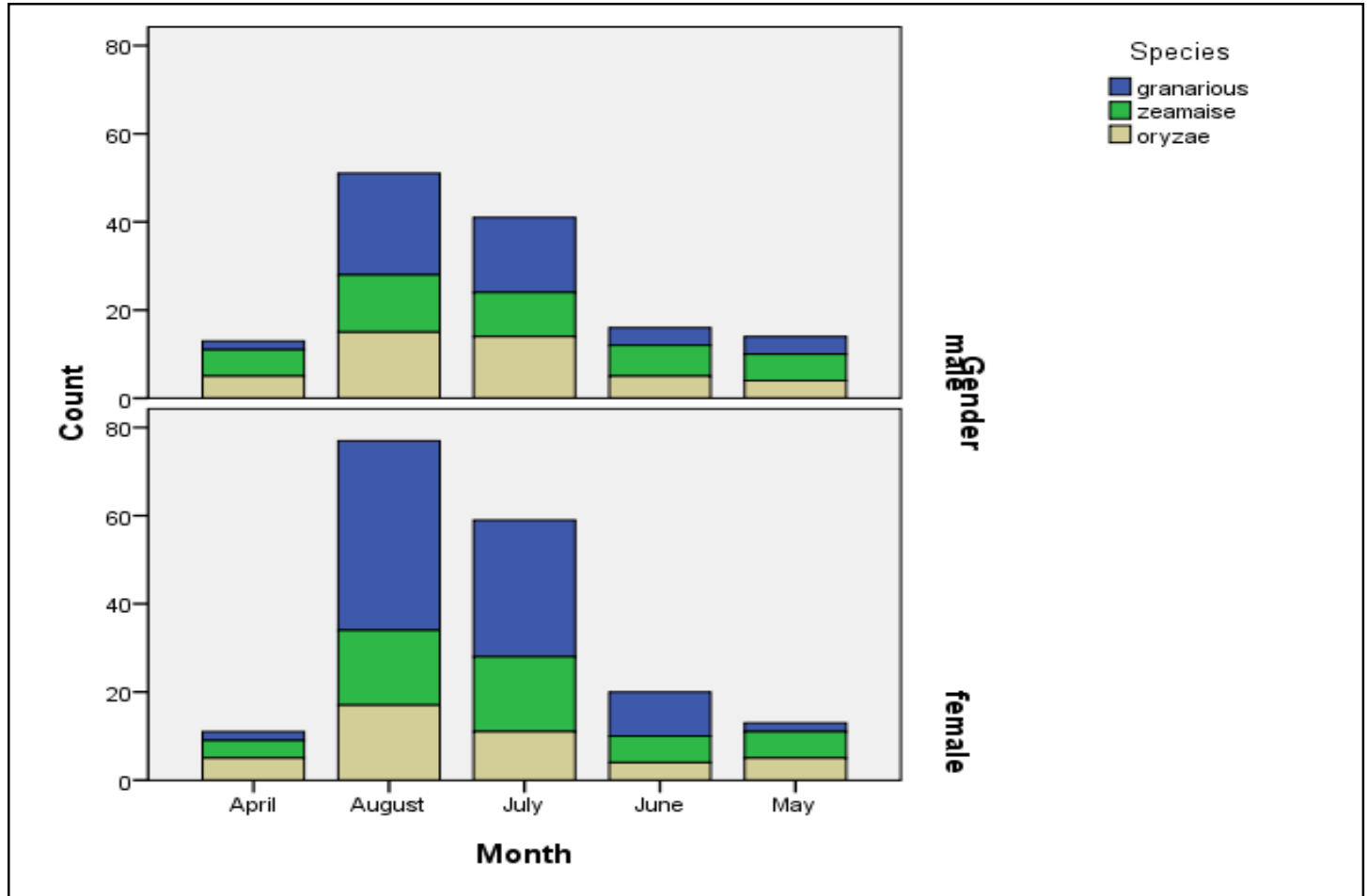

Graph 2. Showing gender wise distribution of weevils in 5 months

Table 1. Showing relation between temperature and population of weevils in 5 months

\begin{tabular}{|c|c|c|c|}
\hline Months & Temperature & Population & Correlation \\
\hline April & 29.23 & 24 & \multirow{2}{*}{0.697801} \\
\hline May & 30.52 & 28 & \\
\hline June & 36.52 & 36 & \\
\hline July & 35.65 & 100 & \\
\hline August & 36.59 & 128 & \\
\hline
\end{tabular}


Table 2. Showing correlation between humidity and population of weevils in 5 months GRAPHS

\begin{tabular}{|c|c|c|c|}
\hline Months & Humidity & Population & Correlation \\
\hline April & 60 & 24 & \\
\hline May & 60.3 & 28 & \multirow{2}{*}{0.991661} \\
\hline June & 61.2 & 36 & \\
\hline July & 67.2 & 100 & \\
\hline August & 68.1 & 128 & \\
\hline
\end{tabular}

\section{Conclusion and Recommendations}

Out of all rice mills granarius species was most abundant and oryzae was least abundant. Abundance of species varied w.r.t temperature and humidity which increased each following month. The results indicated that Diversity and richness remained constant whereas abundance increased with increasing temperature and humidity. In addition to this storage period also played role i.e. longer the time period of storage more abundant would be species. It was also concluded in this study that female ratio is higher than the male ratio. It is recommended that more work should be carried out to find out Diversity of species of weevils in storages in Tehsil Gujrat so that effective methods can be devised for eradication and prevention of infestation by pests.

\section{Authors' contributions}

Conceived and designed the experiments: $S$ Afsheen \& MF Malik, Performed the experiments: $\mathrm{H}$ Zafar \& $\mathrm{S}$ Mubeen, Analyzed the data: AR Bhatti \& SA Zia, Contributed materials/ analysis/ tools: $S$ Afsheen \& MF Malik, Wrote the paper: H Zafar \& SS Aziz.

\section{Acknowledgement}

Authors are highly thankful to the staff of Department of Zoology for their cooperation.

\section{References}

1. Reisig D \& Bambara S (2011). Insect Pests of Stored Small Grains. Insect Pests of Stored Grain 11: 51-55.

2. Rolf G, Oberprieler R, Adriana E, Marvaldi A, Robert S \& Anderson A (2007). Weevils, weevils, weevils everywhere. In: Zhang, ZQ \& Shear, WA (Eds) Linnaeus Tercentenary:
Progress in Invertebrate Taxonomy. Zootaxa 1668: 491-520.

3. Matthews GA (1993). Insecticide Application in stores. In: Application Technology for Crop Protection. $C A B$ Intern 305-315.

4. Tara JS, Sharma S \& Kour R (2010). A Record of Weevil (Coleoptera: Curculionoidea) Diversity From District Samba ( J \& K ). History 5(3): 391-394.

5. Bbosa D, Kohlhaas KA, Brumm TJ, Bern CJ \& Rosentrater KA (2014). Prediction of maize weevil population growth rate. pp. 10: 1-12.

6. Shar MU, Rustamani MA, Nizamani SM \& Bhutto LA (2011). Red palm weevil (Rhynchophorus ferrugineus Olivier) infestation and its chemical control in Sindh province of Pakistan. African J of Agric Res 7(11): 16661673.

7. Harold H \& Shepard HH (1947). Insects Infesting Stored Grain and Seeds, (June), 31.

8. Nansen C, Flinn P, Hagstrum D, Toews MD \& Meikle WG (2009). Interspecific associations among stored-grain beetles. J of Stored Prod Res 45(4): 254-260.

9. Pereira PRVS, Lazzari FA, Lazzari SMN \& Almeida AA (1994). Comparison between two methods of insect sampling in stored wheat. Proceedings of the 6th International Working Conference on Stored Prod Protec 1: 435-438.

10. Buckingham G \& Passoa S (1985). Flight muscle and egg development in Waterhyacinth Weevils. Vanco 497510. 
11. Tindale NB (1962. The chlorocresol method for field collecting. J Lepid Soc 15: 195-197.

12. Dobie P, Haines CP, Hodges RJ \& Prevett P (1991). Insects and Arachnids of Tropical Stored Products their Biology and Identification (A Training Manual).

13. Bousquet Y (1837). Beetles associated with stored products in Canada: An identification guide.

14. Ahmad DT (1956). Humid Tropics research programme, Problems of the humid tropical regions of Pakistan. United Nations Educational, Scientific and Cultural Organization 1-5.
15. Sharma HC, Alur AS, Reddy CR, Jayaraj K, Varaprasad VJ, Reddy KMV, Reddy BVS \& Rai KN (2007). Management of Sorghum and pearl millet pests in bulk storage. International Crops Research Institute for the Semi-arid Tropics 24.

16. Danho M, Gaspar C \& Haubruge E (2002). The impact of grain quantity on the biology of Sitophilus zeamais Motschulsky (Coleoptera: Curculionidae): oviposition, distribution of eggs, adult emergence, body weight and sex ratio. $J$ of Stored Prod Res 38(3): 259-266. 